\title{
Extraction without tooling around - The first comprehensive description of the foraging- and socio-ecology of wild Goffin's cockatoos (Cacatua goffiniana)
}

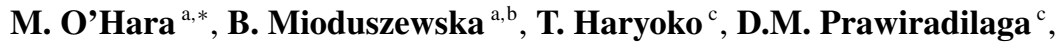 \\ L. Huber ${ }^{a}$ and A. Auersperg ${ }^{a}$ \\ ${ }^{a}$ Comparative Cognition, Messerli Research Institute, University of Veterinary Medicine \\ Vienna, Medical University Vienna, University of Vienna, Veterinaerplatz 1, \\ 1210 Vienna, Austria \\ ${ }^{\mathrm{b}}$ Max Planck Institute for Ornithology, Eberhard-Gwinner-Straße, \\ 82319 Seewiesen, Germany \\ ${ }^{c}$ Research Center for Biology, Indonesian Institute of Sciences, Jl. Raya Jakarta - Bogor \\ Km.46 Cibinong 16911 Bogor, Indonesia \\ *Corresponding author's e-mail address: mark.ohara@vetmeduni.ac.at
}

Received 7 June 2018; initial decision 14 August 2018; revised 8 October 2018; accepted 9 October 2018; published online 24 October 2018

\begin{abstract}
When tested under laboratory conditions, Goffin's cockatoos (Cacatua goffiniana) demonstrate numerous sophisticated cognitive skills. Most importantly, this species has shown the ability to manufacture and use tools. However, little is known about the ecology of these cockatoos, endemic to the Tanimbar Islands in Indonesia. Here we provide first insights into the feeding- and socio-ecology of the wild Goffin's cockatoos and propose potential links between their behaviour in natural settings and their advanced problem-solving capacities shown in captivity. Observational data suggests that Goffin's cockatoos rely on a large variety of partially seasonal resources. Furthermore, several food types require different extraction techniques. These ecological and behavioural characteristics fall in line with current hypotheses regarding the evolution of complex cognition and innovativeness. We discuss how the efficiency of (extractive) foraging may preclude tool use in wild Goffin's cockatoos, even though the corresponding cognitive and ecological prerequisites seem to be present.
\end{abstract}

Keywords

Goffin's cockatoo, Tanimbar corella, foraging ecology, extractive foraging. 


\section{Introduction}

Captive Goffin's cockatoos (Cacatua goffiniana) exhibit a series of advanced cognitive abilities. Studies focusing on impulse control (Auersperg et al., 2013b), the ability to follow invisible object trajectories (Auersperg et al., 2014), reasoning based on inferences in different contexts (Auersperg et al., 2013a; O'Hara et al., 2015), sequential problem solving (Auersperg et al., 2013a, b) and extensive combinatory object play (Auersperg et al., 2014a, 2015) highlight various areas of cognition in which this species has proven proficient. Most notably, these animals have innovatively manufactured and used tools (Auersperg et al., 2012; see also Osuna-Mascaró \& Auersperg, 2018). Tool use innovations can be transmitted to naïve individuals by emulation learning and tool-using subjects are thereafter able to independently innovate tool manufacture (Auersperg et al., 2014). The birds respond flexibly, not only when choosing a tool, but also when making different tools from different materials depending on the problem at hand (Auersperg et al., 2016; Laumer et al., 2016, 2017; Habl \& Auersperg, 2017; Auersperg et al., in press). It was also shown that they keep their tools safe in between foraging bouts (Auersperg et al., 2017). A crucial next step for our understanding of why these cognitive abilities exist in Goffin's cockatoos is to investigate the ecological framework in which this species has evolved. Therefore, we try to examine environmental factors that might have driven the Goffin's cockatoos behavioural flexibility which has led to the innovation of tool use in captivity (Auersperg et al., 2012).

Several researchers (Biro et al., 2013; Call, 2013) emphasise the necessity to distinguish between "stereotyped" and "flexible" tool use, which may represent two opposing extremes along a continuum as both types of tool use have arguably formed as a result of different selection pressures (Alcock, 1972; Hunt et al., 2013). Stereotyped tool use is often shared on a specieswide level and seems to involve a genetic predisposition, which has been suggested to initially result from object related mechanical actions (Hunt et al., 2013) with an adaptive value large enough to become naturally selected for (Biro et al., 2013). In contrast, flexible tool use may involve individual learning which can subsequently be spread socially and thus must not necessarily be adopted throughout the whole population (Biro et al., 2013).

While classical interpretations of tool use refer to it as the employment of an external object to manipulate a target (object, substrate or another individual; see St Amant \& Horton, 2008; Shumaker et al., 2011), a recently pro- 
posed approach reconceptualises the phenomenon by considering "tooling" a special form of problem solving. Here researchers emphasise the role of the motor-action rather than the object used as tool (Fragaszy \& Mangalam, 2018). Despite the ongoing debate on the definition of tool use (Hansell \& Ruxton, 2008; St Amant \& Horton, 2008; Smith \& Bentley-Condit, 2010; Shumaker et al., 2011; Crain et al., 2013; Fragaszy \& Mangalam, 2018), some converging hypotheses have been proposed to explain the evolutionary emergence of this behaviour. These cover three aspects: (i) ecological factors shaping the cognitive abilities required to use tools (Seed \& Byrne, 2010; Biro et al., 2013; Hunt et al., 2013; Fragaszy \& Mangalam, 2018) and regulating the utility of such behaviours (Orenstein, 1972; Tebbich et al., 2002; Hansell \& Ruxton, 2008); (ii) morphological factors constraining or promoting the use of objects as tools (Troscianko et al., 2012; Biro et al., 2013; Matsui et al., 2016; Fragaszy \& Mangalam, 2018); and (iii) social criteria which are important for the spread and maintenance of innovative behaviours (Fox et al., 2004; Biro et al., 2013).

A prominent hypothesis for the evolution of tool use (Parker \& Gibson, 1977; King, 1986; Parker, 1996; see Huber \& O'Hara, 2016 for a summary) explains the use of tools as an adaptation to extractive foraging. Ultimately, this hypothesis considers extractive foraging an important driver promoting the evolution of primate intelligence. Experimental approaches further suggest that food extraction alongside other ecological factors, such as seasonal variability and habitat complexity may promote behavioural flexibility, advanced problem solving abilities and innovativeness (Greenberg, 2003; Tebbich et al., 2010; Griffin \& Guez, 2014; Diquelou et al., 2015; Tebbich et al., 2016). However, these approaches do not necessarily imply specific cognitive adaptations to tool use (Teschke et al., 2011). Others have discussed food caching (Kenward et al., 2011) or nest building (Hansell \& Ruxton, 2008) as potential behavioural predispositions for the development of tool use in birds. Ecological factors, such as the presence of high quality and difficult to access food items, along with unoccupied niches and reduced predation risk may represent an opportunity where the benefits outweigh the costs of using tools (Orenstein, 1972; Tebbich et al., 2002; Kenward et al., 2004; Hansell \& Ruxton, 2008; Kacelnik et al., 2009; Rutz \& St Clair, 2012). In the most extensively studied avian tool user to date, the New Caledonian crow, tool use has been linked to the exploitation of a niche usually occupied by woodpeckers (Orenstein, 1972): wood boring larvae are a major, 
otherwise inaccessible, source of protein and lipids (Rutz et al., 2010). Additionally island species face less predatory pressure, lowering the costs for neophilia and exploratory behaviours (Greenberg, 2003), which might have facilitated the evolution of tool use in New Caledonian crows (Kacelnik et al., 2009). Among other factors, a lack of predators has also been argued to promote tool use in captive animals (Haslam, 2013).

Morphological characteristics such as straight bills allow New Caledonian crows (Corvus moneduloides) to hold a tool in a position that places it in the centre of their binocular vision (Troscianko et al., 2012). While this is considered as an important adaptation (Matsui et al., 2016) for complex object manipulations, captive experiments have shown that parrots are capable of fine-tuned manipulations by employing their sensitive tongue in a thumblike fashion, despite the curvature of their beaks (Auersperg et al., 2011a; Auersperg, 2015).

Social factors such as proximity between individuals, a potential for social learning and other group specific mechanisms allow for the transmission and maintenance of innovative behaviours (Fox et al., 2004), which (if adaptive) may be adopted throughout a population (Biro et al., 2013).

While tool innovations are possible in captive and potentially wild Goffin's cockatoos (Auersperg et al., 2012; Osuna-Mascaro \& Auersperg, 2018), tool use has not been observed on a population wide level in this species. Henceforth, these birds are not assumed to be specialized tool users as for example New Caledonian crows (Rutz et al., 2010). Furthermore they lack the two behavioural predispositions that have been suggested to have prompted the onset of tool use in birds, namely nest building (Forshaw \& Cooper, 1989; Hansell \& Ruxton, 2008) and food caching (Kenward et al., 2011). However, while we could assume that the Goffin's cockatoos are cavity nesters as the vast majority of parrots, little was known about the details of their nesting behaviour in the wild prior to our present study. In fact, the ecology of the Goffin's cockatoo remained largely unknown before we started our field research on this species (however, see Mioduszewska et al., submitted). Present knowledge from captivity suggests that the tool-related capacities of Goffin's cockatoos stem from domain general processing, which, in turn, could represent an adaptation to opportunistic extractive foraging (Laumer et al., 2017).

The Goffin's cockatoo poses an interesting model species to study the ecological prerequisites for domain general intelligence and flexible problemsolving capacities, because: 
(i) The socio-ecology of most parrots includes attributes that are considered indicators of complex intelligence in animals, such as variable/unpredictable environments, long life spans, extended parent-offspring association, high encephalization quotients, high neuronal density and high innovation rates relative to other avian groups (Lefebvre et al., 1997; Lefebvre \& Bolhuis, 2003; Lefebvre et al., 2004; Emery, 2006; Olkowicz et al., 2016).

(ii) Island dwelling species are particularly promising candidates to study innovative problem solving derived from domain general intelligence, as they exhibit decreased neophobia and high exploration rates (Greenberg \& Mettke-Hofmann, 2001; Mettke-Hofmann et al., 2002, Greenberg, 2003) and may therefore fill unoccupied niches by adaptive radiation (Losos \& Ricklefs, 2009).

As mentioned earlier, despite the growing interest and recent insights into the Goffin's cockatoo's cognitive abilities, relatively little is known about their natural behaviour in the wild. The Goffin's cockatoo is a highly social parrot that is endemic to the Tanimbar archipelago in Indonesia and has an estimated population size of approximately 230000 individuals remaining in their natural habitat, mainly in forests, shrubs and on agricultural fields (Jepson et al., 2001). Based on our pilot research (Mioduszewska et al., submitted) and previous records on other corella species, they can be considered feeding generalists (Forshaw \& Cooper, 1989). Although previous to this study, the Goffins' ecology has not been systematically studied in the field, investigating how cognitive capacities found in laboratory experiments correspond to the Goffin's cockatoos' ecology is an important step towards understanding the origins of their technical problem-solving abilities. Animals may acquire a large repertoire of object manipulations throughout their lives that they can flexibly resort to as an adaptation to an opportunistic lifestyle. This seems to apply in particular to generalist species that maintain complex or experimental object play throughout their adult life such as some parrots (see Auersperg et al., 2015 for a review). An extreme example is the kea (Nestor notabilis), a highly opportunistic and neophilic New Zealand mountain parrot that shows advanced physical problem-solving abilities (Diamond \& Bond, 1999; Huber \& Gajdon, 2006; O'Hara et al., 2012) and even simple forms of tool use in the laboratory (Werdenich \& Huber, 2006; Auersperg et al., 2011). 
An important aim of this study was to target the afore mentioned ecological preconditions that have been argued to promote the evolution of flexible problem solving and culminated in the innovation of tool use in captive birds (Auersperg et al., 2012). Since morphology does not seem to pose a constraint in this species, we mainly focus on the first and third preconditions, namely the environmental factors leading to cognitive prerequisites, as well as social interactions and ecological factors regulating the utility of tool use.

We hypothesize that the Goffin's cockatoos' advanced object manipulations in captivity are partially resulting from their foraging ecology: we expect the Goffin's cockatoos to face diverse foraging challenges in a complex, unpredictable habitat. Consequently, we predict this species to have a highly opportunist/generalist feeding ecology, similar to the New Zealand kea (Brejaart, 1988; Greer et al., 2015), while relying on various different seasonal food sources in the wild. As mentioned earlier, ecological circumstances that may promote the utility of flexible tool use are the presence of high quality embedded food and an unoccupied niche to exploit these resources (Orenstein, 1972; Tebbich et al., 2002; Kenward et al., 2004; Hansell \& Ruxton, 2008; Kacelnik et al., 2009; Rutz \& St Clair, 2012). We thus predict to find diverse modes of foraging techniques and/or extractive foraging, in wild individuals.

As mentioned earlier, social interactions of group living individuals can provide the opportunity for the transmission of newly acquired behaviours (Biro et al., 2013). Researchers have assumed that Goffin's cockatoos exhibit a similar social structure as their more widely studied close relatives, the Western long-billed corella (Cacatua pastinator; Cahyadin et al., 1994). Therefore, we expect Goffin's cockatoos to exhibit various levels of social organisation, as described for the western long-billed corella. This species forms breeding pairs, small family groups and larger, locally nomadic juvenile flocks (Smith \& Moore, 1992).

\section{Methods}

\subsection{Study site}

The Tanimbar Archipelago is a small island group $\left(5082 \mathrm{~km}^{2}\right)$ in the Maluku province of Indonesia (approx. $425 \mathrm{~km}$ east of Timor and about $725 \mathrm{~km}$ west of Irian Jaya and $350 \mathrm{~km}$ north of Darwin, Australia). We have been carrying out our research on Yamdena, the largest of the Tanimbar islands (approx. 


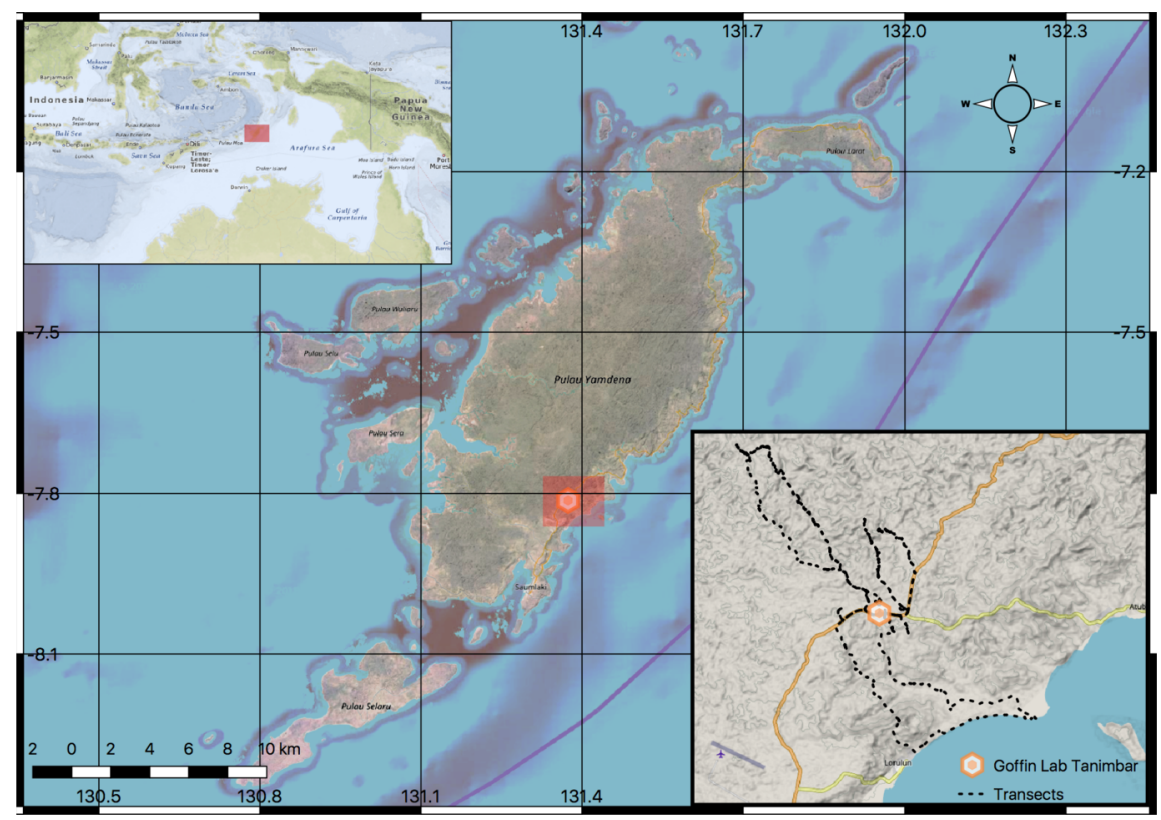

Figure 1. Overview of the research location and transects represented by dashed lines.

$2981 \mathrm{~km}^{2}$; see Figure 1). The islands are characterized by uplifted reeflimestone formations that have emerged during the Pleistocene (Monk et al., 1997). Vegetation biomes encompass agricultural land with fruit tree plantations and dry land agriculture (especially along the coastline), mangroves, savannah patches and larger patches of primary and secondary monsoon forest (personal observation). Forests are mainly deciduous monsoon forests (discontinuous canopy of tall trees at $>30 \mathrm{~m}$ with continuous canopy of smaller trees at $10 \mathrm{~m}$ ) and mosaic forests, a mixture of monsoon- and semievergreen forests (Cahyadin et al., 1994). The climate is characterized by two rain seasons from December to March (West Monsoon) and May to September (East Monsoon) and a dry season from September to December. An additional short dry season occurs during the shifting of wind directions in April. However, this strict temporal distinction is not consistent for each year, with potentially longer rainy seasons or extended dry seasons (personal communication with locals and personal observation). We established a field station on the fields of Lorulun village $\left(7^{\circ} 48^{\prime} 59.3^{\prime \prime} \mathrm{S}, 131^{\circ} 22^{\prime} 41.2^{\prime \prime} \mathrm{E}\right)$, with the permission and collaboration of local farmers and the local government. This station included a capture-release aviary to investigate behavioural in- 
novations of wild-caught Goffin's cockatoos (manuscript in prep.). The agricultural grounds of the Lorulun village are frequently visited by flocks of Goffin's cockatoos and provide access to primary and secondary forest via old logging routes and hunting paths.

\subsection{Data collection}

We have established a grid of transect routes within a $6 \mathrm{~km}$ radius of the field station (see Figure 1 for an overview). These routes incorporated agricultural areas, logged secondary forest, as well as primary forest and mangrove habitats. Thus, this grid allowed us to scan a representational sample of potential Goffin's cockatoos' foraging environments on Yamdena. We used habitat types classified as: Forest (with dense foliage and continuous canopy above $15 \mathrm{~m}$ ), Fields (agricultural fields), Shrubs (continuous foliage with a max. height of $3 \mathrm{~m}$ and a discontinuous canopy and interspersed trees $>10 \mathrm{~m}$ ), Grassland (open areas covered predominantly in Alang-Alang (Imperata cylindrica), with interspersed coconut trees). Data were collected between 1 January 2017 and 22 November 2017. Behavioural scanning was focused on times with highest activity patterns (Jepson et al., 2001), from sunrise (approx. 5:30) to 9:30 and in the afternoon at 14:30 to sunset (approx. 18:30). However, on regular occasions (10\%) throughout the year we randomly extended scanning times of morning and afternoon scans to include midday (10:00-14:00) observations in order to validate proposed circadian activity patterns.

Scanning was performed by one (MO) or two observers (MO and BM). As scanning was conducted together and scored live in the field inter-observer reliability could not be assessed. We employed a continuously alternating approach of slowly walking along transects and point observations, concealing ourselves in hideouts, at positions with known activity (from walking transects). This approach allowed us to maximise the quality of observations of behaviours (at observation points): during walking transects individuals of cockatoos often flew off if they noticed us before we managed to conceal ourselves successfully (these incidents were later scored as 'flying'). However, continuously walking the transects enabled us to identify areas of increased activity and avoid overrepresentation of few locations.

For any visual encounters with Goffin's cockatoos (also referred to as sightings) time, location, duration (in seconds), number of individuals and rough behavioural categories were noted on paper and later digitalised at the 
field station. The behavioural categories recorded included: Flying (flying off or over), Perching, Foraging, Preening (self-preening or allopreening), Substrate Manipulation (biting objects/bark without visible ingestion, removing litter, digging) and Playing (social and solitary play). An observation of birds was continued until all individuals were out of sight, or if they showed behavioural signs of stress in sensitive areas (e.g., alarm calls at nesting sites). Locations were recorded using a Garmin Tactix ${ }^{\circledR}$ smartwatch with high sensitivity GPS-positioning. Videos and photographs were taken opportunistically using a Canon EOS 7D Mark II camera with a Canon EF 100-400 mm f/4.5-4.6L IS II USM lens.

Food sources were classified as 'confirmed' if direct observations of birds ingesting material could be made, whereas items for which only indirect evidence was available (such as bite marks on objects at locations with immediate preceding bird activity, or that were reported to be consumed by cockatoos by two independent local sources) were considered as 'suggested' food items. Food samples and corresponding available parts of plants (stem, leaf, flower and fruit) were photographed for later identification, sampled and their seasonal availability was assessed from locals' reports.

Nest trees were climbed during times when parent individuals were absent in order not to disturb breeding activities, using a Gleistein GeoStatic 10.5 Semistatic rope $(80 \mathrm{~m})$ with a Petzl AscensionR handheld ascender and a Petzl I'D S self-breaking belay device. Height and width of nest-holes, diameter of trees and size, as well as direction of nest-hole openings were measured using a commercial steel measuring tape. Nest status was assessed by shortly filming the hollow using a GoPro Hero3 camera mounted on an extension.

\subsection{Statistical analysis}

To validate circadian activity patterns, we combined the number of observations during the morning (5:30-9:30), midday (10:00-14:00) and afternoon (14:30-18:30). We performed pairwise Wilcoxon rank sum tests to analyse differences between daily categories (morning, midday and afternoon), adjusting $p$-values using the "holm" method to correct for multiple testing. Encounters per hour were compared via $\chi^{2}$ contingency tests in order to explore associations between time and habitat (as described above), social structure (categorised as Individuals, Pairs and Groups $\geqslant 3$ individuals), behaviours (as specified above) and season (Rain or Dry season, as mentioned above). 
Mixed models were used to investigate the effect of habitat, behaviours, social structure and season, as well as their interactions as fixed factors, on log transformed (to satisfy model-assumptions regarding normality of residuals) relative number of encounters (encounters divided by the times specific sites were sampled) and included sites as random variable to account for repeated observations at the same location. Model selections were based on stepwise backward model refinement from a full model and comparisons of the Akaike Information Criterion (AIC). Statistical models were carried out using the lme 4 package and model assumptions were confirmed visually employing the mcp.fnc function of the lmer.convenience package. To test for overdispersion of data in mixed models we employed a function calculating the equivalent to the overdispersion parameter theta (see SEM for details).

Foraging observations were compared via $\chi^{2}$ contingency tests in order to explore associations between habitat, social structure and season. To investigate if the number of individuals within groups (Group size) would differ between habitats we used pairwise Wilcoxon rank sum test and adjusted $p$-values for multiple testing using the "holm" correction method.

All statistical analyses were carried out in $\mathrm{R}$ version 3.4.3 (R Core Team, 2017) and graphs were created by employing the 'ggplot' function (Wickham, 2009) and 'mosaic' function of the vdc-package (Meyer et al., 2006).

Geo spatial information was processed using QGIS 3.0.2 - Girona, employing the WSG 84 coordinate reference system (CRS) and EPSG: 3857 for spatial reference. Base-maps rely on Thunderforest Landescape data (Maps (C) www.thunderforest.com, Data (C) www.osm.org/copyright) with satellite imagery from Google Maps and hill shade layers are based on MapSurfer (SRTM, ASTER GDEM is a product of METI and NASA, Imagery GIScience Research Group at Heidelberg University).

\section{Results}

\subsection{General behaviour, location and time}

During our scanning activities of $366 \mathrm{~h} 31 \mathrm{~min}$, we were able to record a total of $96 \mathrm{~h} 32 \mathrm{~min} 17 \mathrm{~s}$ of behavioural observations (mean \pm SE 3 min $22 \mathrm{~s} \pm$ 33 s per observation) during 1194 visual encounters (including re-sightings, as individual identification was not possible). We could confirm daily activity patterns with two peak occurrences, differing significantly from the lower number of midday observations, during the morning ( $W=5638, p<0.001$, 
$r=-0.34)$ and in the afternoon $(W=2316.5, p<0.001, r=-3.43)$. No difference in activity was observed between the morning and afternoon ( $W=9743, p=0.42, r=-0.31$; Figure 2a). However, analysing the effect of different factors on the number of sightings over the day revealed a significant association with habitat use $\left(\chi_{36}^{2}=57.39, p=0.013, \varphi=0.22\right)$. This effect seems to be driven by the larger than expected number of observations in the forest during the midday and more observations in the grassland in the early morning compared to the other habitats (see Figure $2 b$ ). Social structure $\left(\chi_{24}^{2}=30.67, p=0.164, \varphi=0.20\right)$, season $\left(\chi_{12}^{2}=8.59, p=0.737\right.$, $\varphi=0.15)$ and behaviours $\left(\chi_{60}^{2}=51.61, p=0.771, \varphi=0.17\right)$ showed no such association with habitat.

Regarding encounters corrected for number of site visits, a model including behaviour, social structure and the interaction between season and habitat as fixed factors and sites as a random factor yielded the best fit $\left(\mathrm{R}_{\mathrm{m}}^{2}=0.349, \mathrm{R}_{\mathrm{c}}^{2}=0.685\right)$ with no overdispersion $(\theta=0.41)$. Behaviours $\left(\chi_{5}^{2}=95.01, p<0.001\right)$ constituted mainly of flying and perching, which were recorded significantly more often than other behavioural categories, which were observed at similar frequencies (see Table A1 in the Appendix for detailed contrasts). Social structure $\left(\chi_{2}^{2}=21.87, p<0.001\right)$ revealed significantly more sightings of solitary individuals than groups $(\beta=0.21$, $\mathrm{SE}=0.09, p=0.043)$, and pairs $(\beta=0.43, \mathrm{SE}=0.09, p<0.001)$, as well as marginally more occurrences of groups than pairs $(\beta=0.22, \mathrm{SE}=0.09$, $p=0.052$ ) within the study area (see Figure 3 for a geospatial representation of behaviours and sociality). Finally, the interaction of habitat and season had a significant effect on how often sightings could be made $\left(\chi_{3}^{2}=17.81\right.$, $p<0.001)$. Significant differences can be seen between sightings for both seasons (see Figure 4 and Table A2 in the Appendix for detailed contrast results), but notably also within the grassland habitat between seasons. In this habitat, significantly more observations were made during the dry than the rainy season $(\beta=1.27, \mathrm{SE}=0.32, p=0.002)$.

\subsection{Foraging}

Analyses focusing on observations of foraging behaviours revealed an association of habitat with social structure $\left(\chi_{6}^{2}=14.62, p=0.023, \varphi=0.38\right)$ and habitat with season $\left(\chi_{3}^{2}=20.65, p<0.001, \varphi=0.64\right)$. This effect is driven by a higher number of encounters than expected during the wet season on fields, and during the dry season in the forest and grassland. More 

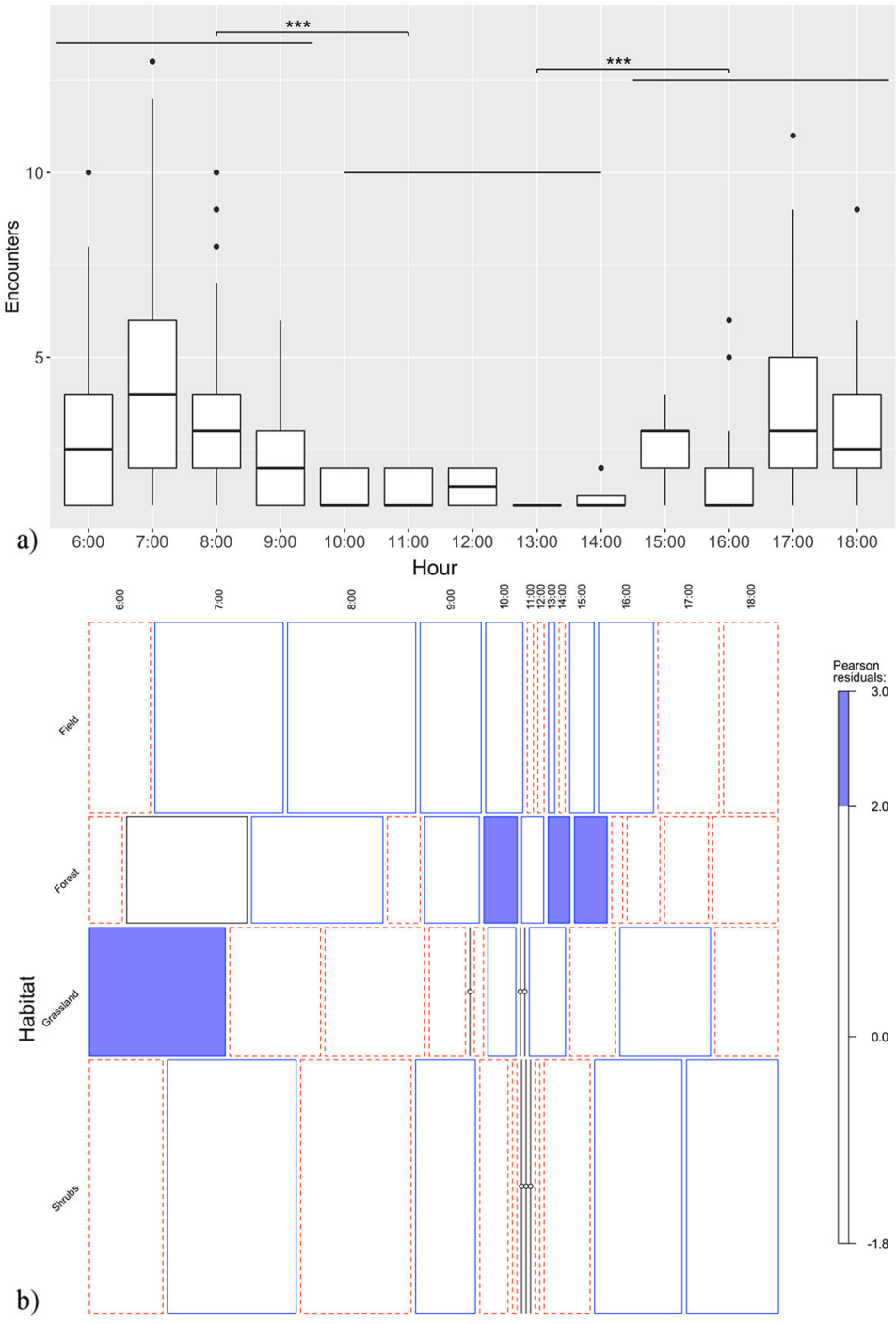

Figure 2. (a) Number of sightings per hour within a day; horizontal lines indicate group comparisons; bold horizontal lines indicate median values, boxes span the first to third quartiles, whiskers represent $95 \%$ confidence intervals and dots represent outliers; ${ }^{* * *} p<0.001$, ${ }^{* *} p<0.01$ and $* p<0.05$ (adjusted for multiple comparisons). (b) Mosaic plot of observations within a day by habitat; size of each rectangle represents frequency of encounters by habitat and time (hour); dark shading indicates significant deviation in number of encounters compared to the expected frequency (residuals $>2$ ); blue shadings and continuous lines refer to larger numbers of encounters than expected, red shading and broken lines indicate lower numbers of encounters than expected in an Equiprobability model. 


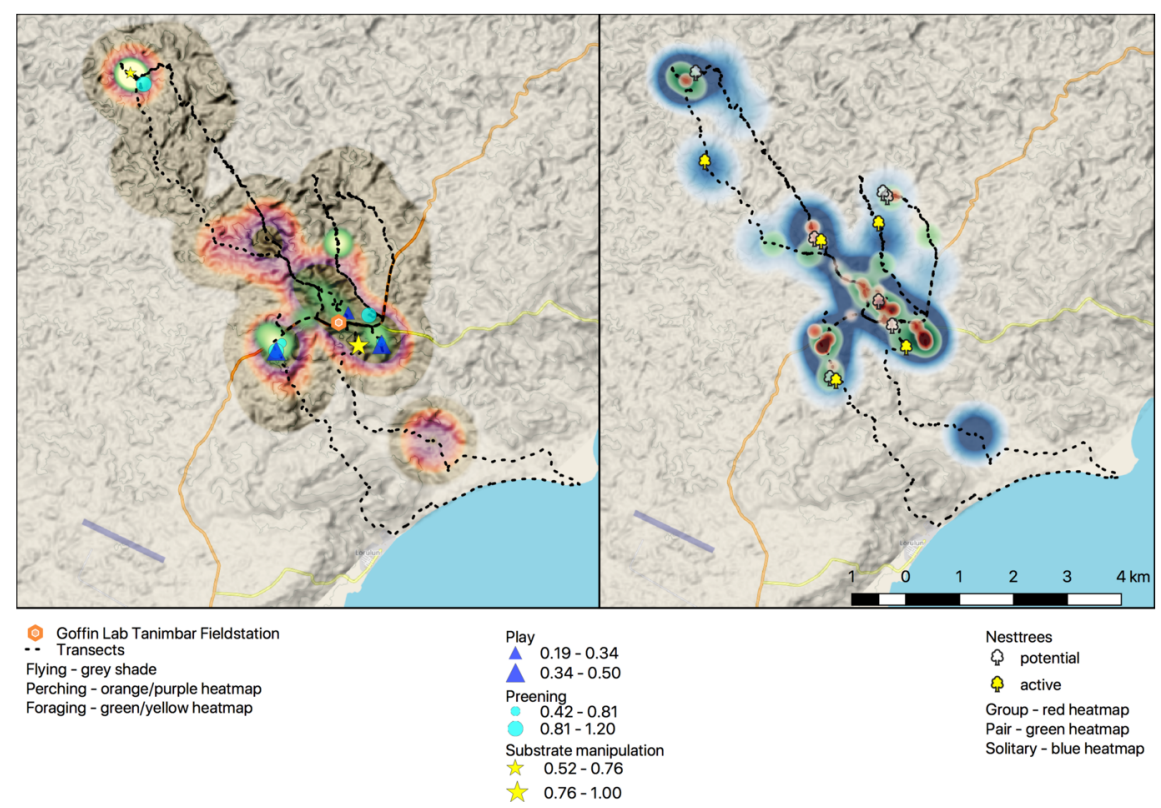

Figure 3. Geospatial overview of behavioural observation (left) and different social categories encountered (right); grey shaded areas indicate presence of flying individuals; orange to purple represents areas were perching occurs; in green to yellow locations with most observed foraging events have been observed; further behaviours are depicted differing in size depending on the frequency of occurrences; numbers provided correspond to the relative number of observations (encounters divided by site visits).

sightings of solitary individuals and pairs occurred in the forest and more single individuals were observed in the grassland. However, on fields more groups were encountered than in other habitats (see Figure 5a for a combined representation).

Overall, group sizes ranged from 3 to 95 individuals with a median of 4 individuals. However, there were significantly greater numbers of individuals observed in groups on fields than in the forest ( $W=1671, p=0.005, r=$ -0.21 ) and shrubs ( $W=10474, p<0.001, r=-0.28)$, but did not differ between other habitats (see Figure $5 b$ ).

During scanning we have encountered a total of 67 different potential food sources, many of which are yet to be identified to species level and sometimes only local names are currently available. Of these food-items 32 could be confirmed to be part of the cockatoos' diet by direct observations. For a further 35 plants, there is indirect evidence of being part of the diet (found 


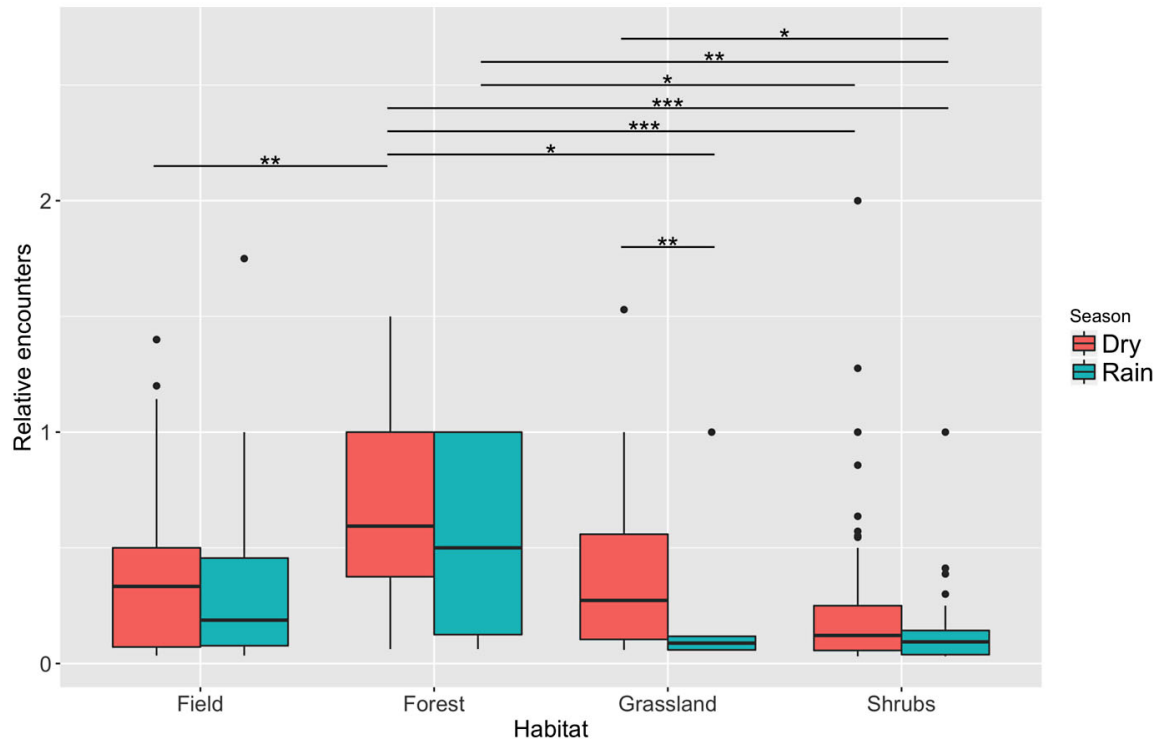

Figure 4. Number of observations (weighed for the number of specific site visits) at different habitats during the dry (red) and rain (green) season; bold horizontal lines indicate median values, boxes span the first to third quartiles, whiskers represent $95 \%$ confidence intervals and dots represent outliers; horizontal lines indicate group comparisons; ${ }^{* * *} p<0.001$, ${ }^{* *} p<0.01$ and ${ }^{*} p<0.05$ (adjusted for multiple comparisons).

partially consumed at roosting spots or being reported by locals to be eaten by the cockatoos). While several of the confirmed items occur in multiple habitats, the forest provides the largest variety of fruit, whereas fields provide mainly seeds and shrubs provide mainly seeds and inflorescence, including leaves and young stems. Seasonality affects mainly fruit and seeds, as only 5 plant species carry fruit all year (see Figure 6). Amongst the confirmed food items, we could identify at least 3 that require extractive foraging techniques to reach the edible components. All of these items are available throughout the year:

The cassava plant (Manihot esculenta), originating from South America (Olsen \& Schaal, 1999), has been introduced to Asia by Spanish and Portuguese traders during the 18th century (Onwueme, 2002) and has ever since been a common and easily cultivated crop. Although Goffin's cockatoos consume young stems and leaves of this plant, the most nutritional part is the roots. The large starch containing tubers lie several centimetres underground and are excavated by the Goffin's cockatoos by continuous biting at the bot- 

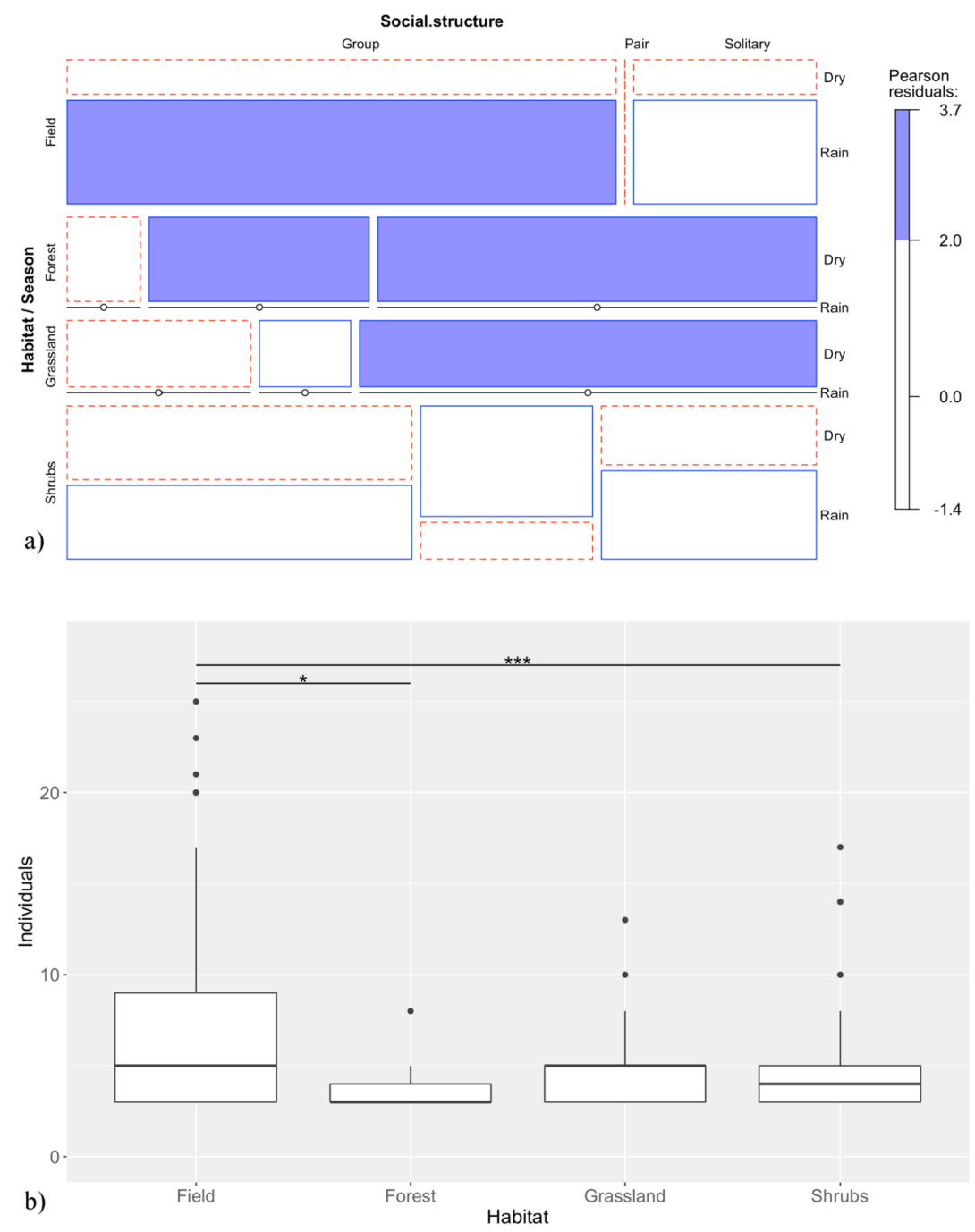

Figure 5. (a) Mosaic plot of encounters by social structure (group, pair or solitary) in different habitats and seasons; size of each rectangle represents frequency of encounters); dark shading indicates significant deviation in number of encounters compared to the expected frequency (residuals $>2$ ); blue shadings and continuous lines refer to larger numbers of encounters than expected, red shading and broken lines indicate lower numbers of encounters than expected in an Equiprobability model; (b) number of individuals within groups for different habitats; bold horizontal lines indicate median values, boxes span the first to third quartiles, whiskers represent $95 \%$ confidence intervals and dots represent outliers; note that the $y$ axis is limited to 27 for better comparability; horizontal lines indicate group comparisons; ${ }^{* * *} p<0.001$, ${ }^{* *} p<0.01$ and ${ }^{*} p<0.05$ (adjusted for multiple comparisons). 

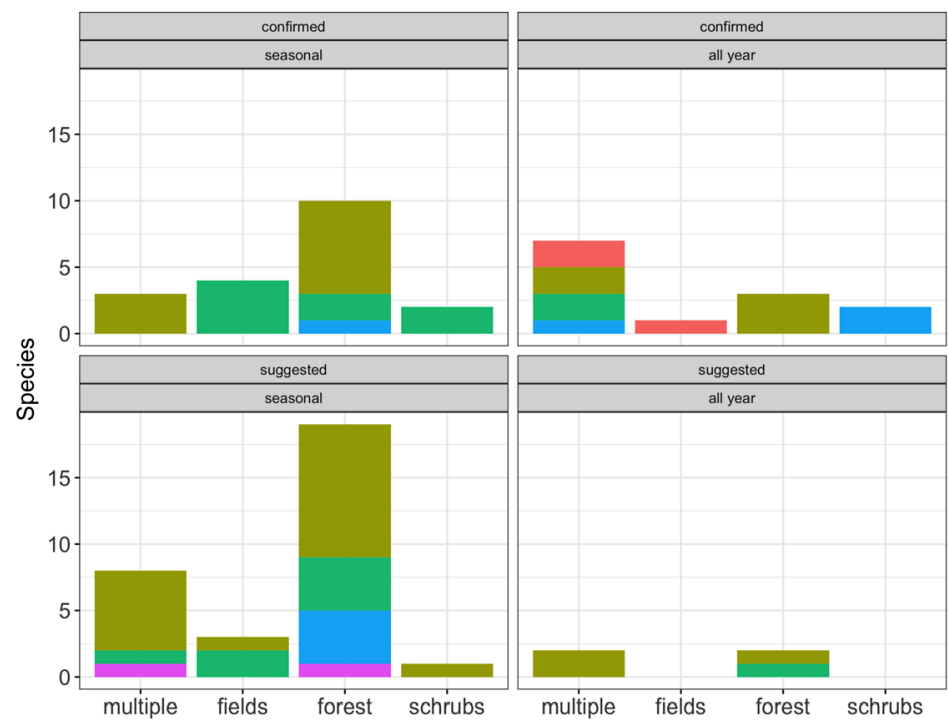

Extractive

Fruit

Seeds

Inflorescence

unknown

Figure 6. Number of different plant species with main abundance in different habitats separated by seasonality (seasonally or all year available) and feeding status (confirmed or suggested); proportion of parts that are ingested are indicated by colour.

tom of the plant and by shovelling pieces of soil with the beak (see Video 1 at $10.6084 / \mathrm{m} 9$.figshare.7217741).

Coconut trees (Cocos nucifera) are native to Indonesia and available throughout the island but are cultivated in larger quantities on grasslands. Typically, cockatoos search for young fruit that have not yet developed a hardened endocarp. Nevertheless, in order to access the endosperm and fruit water (see Video 2 at 10.6084/m9.figshare.7217741) birds search for or incur small incisions to the leathery exocarp and begin tearing stripes of the thick fibrous mesocarp. This process may take several hours or even days, with interruptions during which individuals come back repeatedly, until a hole big enough to fit the Goffin's head is produced.

Wild individuals have also been observed to remove tree bark and to dismantle rotting tree trunks, which would qualify as extractive foraging if it was aimed at retrieving food, such as insects. However, during the sampling period we have not made any observations of cockatoos foraging on insects in the wild. Nevertheless, we found that the wild-caught birds kept in the capture-release aviary readily and proficiently consumed larvae and pupae of wood-boring beetles (Cerambycidae sp., see Video 3 at 10.6084/m9.figshare. 
7217741). When cavities of decaying tree logs were baited with these larvae birds were persistently biting on the wood and managed to enlarge the tree cavities and extract the bait. Alternatively, when faced with deeper cavities, after visual inspection, they also inserted their long thin toes into holes to extract larvae (see Video 4 at 10.6084/m9.figshare.7217741).

\subsection{Nesting}

In the course of our behavioural observations we encountered 23 trees, containing potential nest holes, of which 5 were active with Goffin's cockatoo chicks and 2 were active with parrot eggs which could not be clearly attributed to a species (most likely C. goffiniana or Eclectus roratus). The timing of observed nesting behaviour (between 11 September 2017 and 4 November 2017) supports our previous estimations of the onset of breeding season between June and July (Mioduszewska et al., data not shown). Tree hollows created by large broken branches were used for nesting and were found at heights between 16.18 and $30.32 \mathrm{~m}$ (median $=27.41 \mathrm{~m}, \mathrm{SD}=$ $5.62 \mathrm{~m}$ ) from the ground. Among the active nest hollows 2 had no substrate and 3 had leaves and fine branches lying loosely on the floor without further structure.

\section{Discussion}

The presented findings are a crucial first step towards describing the ecology of the Goffin's cockatoo and provide preliminary insights to the interplay between its foraging behaviour and its advanced technical capacities. Most importantly, we have found that Goffin's cockatoos feed on a multitude of different resources, a large portion of which is only seasonally available. The distribution of this species in different habitat types confirms previous findings by Jepson et al. (2001) in the 1990s, who concluded that the Goffin's cockatoo was widely dispersed throughout different habitats with most encounters in the forest and on fields. Our current observations add another layer of complexity to the proposed habitat use depending on seasons: The large amount of seasonal food items identified suggests that such a variable habitat use likely depends on changing seasonal food availability in different areas. Coconuts, which are abundant on grasslands, may represent an important source of liquid, especially during harsh dry seasons when availability of water is low due to draughts and there is less fruit in the forest. Coconuts 
are mostly visited solitarily, likely because they pose a not only a valuable but also a challenging resource. Conversely, the appearance of large groups in fields during the end of the two wet seasons coincide with harvesting times for local products, such as corn and green beans. Despite the large number of different (mainly plant) species that already could be confirmed to be part of the Goffins' diet, we acknowledge that our list is most likely not exhaustive. Further studies are necessary to assess the full extent of their dietary composition and future stable isotope analyses may allow us to infer the degree to which each of these resources is exploited. Nevertheless, the current survey of food items consumed by Goffin's cockatoos suggests that they rely on a broad spectrum of resources and therefore may be considered opportunist feeding generalists. This supports our predictions regarding ecological factors (such as seasonal variability and habitat complexity) that have been proposed to play an important role in the evolution of behavioural flexibility, advanced problem solving and innovativeness (Greenberg, 2003; Tebbich et al., 2010, 2016; Griffin \& Guez, 2014; Diquelou et al., 2015).

Several environmental factors have been proposed to represent potential promotors for the evolution and utility of extractive tool use (Rutz \& St Clair, 2012). We have already discussed the seasonal availability of food sources which can drive an opportunistic lifestyle (Tebbich et al., 2002). Others have discussed embedded or difficult to open food (Parker, 2015) and the absence of competitors exploiting this niche as a promotor for tool use (Orenstein, 1972; Kenward et al., 2004). We could show that Goffin's cockatoos use several different extractive foraging modes. There are no specialized extractive foragers such as woodpecker inhabiting the Tanimbar archipelago which usually would occupy this niche. However, other species such as the Tanimbar friarbird (Philemon pulmigenis) have also been observed to share at least once resource with the Goffin that requires extractive foraging during the dry season (personal observation), the coconut. Finally, a reduced risk of predation may lead to reduced costs for exploration and consequently reduced neophobia, a phenomenon especially prevalent in island species (Greenberg \& Mettke-Hofmann, 2001). In turn, this may also facilitate innovations (Greenberg, 2003) and has been suggested as a possible driver for the evolution of tool use in New Caledonian crows (Kacelnik et al., 2009). Besides humans and larger birds of prey, such as brahminy kites (Haliastur indus) and Bonelli's eagle (Aquila fasciata) only few other species on 
Tanimbar seem to pose a threat to the Goffin's cockatoo (personal observations, Mioduszewska et al., submitted). Therefore, the predation pressure, at least on adult Goffin's cockatoos seems relatively low, although a comprehensive account so far is lacking. A study on neophobia and exploration in this species in a captive setting showed that Goffin's cockatoos are mildly neophobic and quite explorative (O'Hara et al., 2017), although a systematic assessment of neophobia in a more natural setting remains to be conducted.

During group foraging events in open spaces, such as on fields, individuals typically aggregate on nearby trees until a critical mass has gathered (approx. 15 individuals) before descending for feeding, which may cause a dilution effect (Williams, 1966; Hamilton, 1971). Temporary large aggregations of individuals and an apparent fission-fusion structure of groups suggests that alongside the environmental complexity, the social structure of this species may represent a promising avenue for further research (e.g., Overington et al., 2008). Our preliminary observations concerning differential social structures, multiple sightings of large groups and interactions within these groups support the notion that these birds might have the possibilities to learn from conspecifics, which has been demonstrated by captive individuals in a previous study (Auersperg et al., 2014). This seems to satisfy the criteria that have been proposed necessary in order for innovations to be transmitted and maintained within a population, such as spatial proximity, a potential for social learning and reduced intraspecific competition (Fox et al., 2004; Biro et al., 2013).

As mentioned earlier, data from controlled studies in captivity have shown that Goffins use objects as tools and socially transmit their tool using skills to other individuals (Auersperg et al., 2012, 2014a, b, c). The thumb-like tongue of the Goffin's cockatoo is extremely dexterous and allows for very sensitive coordination of objects in the beak (Auersperg, 2015). Therefore, limitations with regards to cognitive and morphological constraints for flexible tool use do not seem to play a major role (Hunt et al., 2013).

Thus, we conclude that the ecological framework in which this species evolved would satisfy various criteria that have been argued to underlie tool use in wild individuals (e.g., Shumaker et al., 2011; Biro et al., 2013; Hunt et al., 2013; Fragaszy \& Mangalam, 2018). However, we found none of the behavioural predispositions in wild individuals that have been proposed to promote tool use in birds (Hansell \& Ruxton, 2008; Kenward et al., 2011). Unsurprisingly, no incidents of food caching could be observed and, as the 
Goffins breed in pre-existing tree holes that are sometimes extended with the beak, they do not need to bring objects into functional relationship such as during nest construction from twigs (Hansell \& Ruxton, 2008).

While we were unable to observe instances of tool use within our time on Tanimbar, a recent analysis of a video showed a feral Goffin's cockatoo from an introduced population in Singapore manipulating and combining a stick like object with the inside of a foraging source (open coconut; OsunaMascaró \& Auersperg, 2018). We are also aware that we cannot fully exclude that our total observation time in their original habitat on Tanimbar (ca. 100 hours; cockatoo sightings on Tanimbar are relatively frequent but usually short) might still obscure the presence of tool use in this species. Challenges surrounding field observations of rare behaviours are exemplified in investigations of the percussive tool use of black palm cockatoos (Probosciger aterrimus), a behaviour which is well documented in the literature but also can be recorded only once per 100 hours of observation time (Heinsohn et al., 2017). Here, male cockatoos use sticks for drumming on trees with hollows, which has been suggested to advertise nest quality over large distances (Heinsohn et al., 2017). However, tools for social display are only required for very distinctive purposes that occur infrequently (attracting a mate, deterring an intruder) and only during specific seasons (e.g., mating season). Birds, such as the New Caledonian crow or the woodpecker finch, that use tools habitually for foraging purposes rather than for display show a much higher percentage of tool related behaviours within overall observation times (daily observations in New Caledonian crows; Hunt, 2000). However, other species such as nuthatches express tool using behaviour more rarely or seasonally (Morse, 1964; Gray et al., 2016; Rutz \& Deans, 2018). At this point it is important to note that despite careful awareness and consideration, a potential bias regarding the number of observations in different habitats can never be fully excluded. Birds are more conspicuous in open areas which provide easier access to food that does not require extractive foraging (with exception of the coconuts) and are better concealed in the dense tropical forest habitat. Predation in the dense forest may also be lower than in open areas which, together with the afore mentioned hypothesis of tool use evolving as a result of reduced predation risk, might suggest potential occurrences of tool use to develop predominantly in the forest habitat.

During our pilot expedition in 2015 (Mioduszewska et al., submitted), we were able to record an anecdotal observation of a breeding pair dropping relatively large branches (approx. $64 \mathrm{~cm}$ in length) as humans approached the 
nesting tree within the forest. While the snipping of smaller branches and leaves is quite common and may be part of the play repertoire, dropping of larger branches have only been observed in this context. This may occur as a stereotyped release of agitation in association with the effect of deterring ground predators. However, it will have to remain speculative until further systematic investigations can be made. Even if confirmed, this type of tool use would not require the actor to use an object as a direct, functional extension of the body, which some definitions require (see Fragaszy \& Mangalam, 2018).

Behavioural adaptations are more flexible than morphological adaptations and may thus occur when abrupt shifts in the ecology require a 'shortcut' to exploit resources or solve problems. Hence, innovative problem solving may be facilitated when moving into novel environments (Alcock, 1972). This may apply to tool-like behaviour shown by the feral Goffin's cockatoo in Singapore (Osuna-Mascaró \& Auersperg, 2018). As the human population grows and urban development on the Tanimbar Archipelago proceeds, the natural environment of the Goffin's cockatoo is rapidly changing and the birds are faced with novel situations. More recently a population that has been introduced and successfully established itself in Singapore, is facing potentially very different environmental and anthropogenic challenges. A comparative approach of studying these two populations might provide interesting insights regarding behavioural innovations and adaptations to human induced changes.

The findings elaborated above favour the idea that this species has the cognitive capacity, morphological capability and environmental opportunities for developing tool use in its natural habitat (Hansell \& Ruxton, 2008; Hunt et al., 2013). Nevertheless, the necessity for doing so may be limited. The bill of birds has been subject to evolutionary pressures determining its morphology (e.g., Lamichhaney et al., 2015; Matsui et al., 2016). In this respect, especially the beaks of parrots can be described as 'multi-purpose tools', allowing for great flexibility in their application (e.g., Auersperg, 2015). It may be used to dig up embedded material such as roots by shovelling soil as elaborated earlier. Tree bark can be levered to reach insects or sap and decaying wood can also be easily manipulated with the strong and sharp opposing mandibles. The zygodactyl feet and long digits allow for a good grip and for probing in holes (as described above). Thus, we assume that the morphological adaptations, such as zygodactyl feet and strong and flexible beaks 
mostly suffices for the deconstruction (or 'destruction') of substrate and extraction of food. These features make tool use often - but not completely obsolete.

Darwin and Wallace (Darwin \& Wallace, 1858; Darwin, 1859) have identified how morphological adaptations evolve according to the prerequisites of the environment. Thus, species that may have the cognitive prerequisites to develop tool use will not do so if the morphological adaptations are adequate to succeed at solving the majority of extractive foraging problems in their natural habitat. Goffin's cockatoos lack the morphological adaptations related to tool use, such as straight beaks and stereoscopic vision, that can be found in New Caledonian crows (Kenward et al., 2004; Troscianko et al., 2012; Matsui et al., 2016). Nevertheless, they possess a beak which makes them well adapted for extractive foraging. We suggest that the described socio-ecological and morphological characteristics support their generalist lifestyle and have promoted behavioural flexibility to meet novel environmental challenges including new extractive foraging problems but without an imminent need for using tools.

\section{Acknowledgements}

We are grateful to the Indonesian Government for granting and supporting our research. The fieldwork was conducted under the permit 6D/TKPIPA/FRP/SM/VI/2015 \& 410/SIP/FRP/E5/Dit.KI/XII/2016 granted to Mark O'Hara and Berenika Mioduszewska by the Ministry of Research Technology and Higher Education of the Republic of Indonesia. The Maluku Forestry Office (BKSDA Maluku) allowed this work to be conducted on Yamdena Island and we would like to express our appreciation for the cooperation and help of local forestry officers, Junesly F. Lilipory and Cardolin Lattuputy who supported our scanning efforts in the forest. We would like to express our deep gratitude to Wilhelmus, Vera and Kletus Samangun for their help hosting us in the Lorulun fields, Alowisius Sakliresi, Petrus Sainyakit, Atanasius Sainyakit and Yakobus Sainyakit for invaluable help in the Lorulun forest and fields, to Leo Samangun for his kind involvement in our local outreach work, as well as the people of Lorulun for hearty receiving us to their community. We are very grateful to the editor and two anonymous reviewers for their helpful comments and suggestions how to 
improve the manuscript. This project was fully funded by the Austrian Science Fund (FWF): P 29075 and P 29084 awarded to Alice Auersperg and J 4169 awarded to Mark O'Hara.

\section{References}

Alcock, J. (1972). The evolution of the use of tools by feeding animals. - Evolution 26: 464-473.

Auersperg, A.M.I. (2015). Exploration technique and technical innovations in corvids and parrots. - In: Anim. creat. innov., Vol. 2. Elsevier, p. 45-72.

Auersperg, A.M.I., Borasinski, S., Laumer, I. \& Kacelnik, A. (2016). Goffin's cockatoos make the same tool type from different materials. — Biol. Lett. 12: 20160689.

Auersperg, A.M.I., Huber, L. \& Gajdon, G.K. (2011a). Navigating a tool end in a specific direction: stick-tool use in kea (Nestor notabilis). — Biol. Lett. 7: 825-828.

Auersperg, A.M.I., Kacelnik, A. \& von Bayern, A.M.P. (2013a). Explorative learning and functional inferences on a five-step means-means-end problem in Goffin's cockatoos ( $\mathrm{Ca}$ catua goffini). - PLoS One 8: e68979.

Auersperg, A.M.I., Köck, C., O’Hara, M. \& Huber, L. (n.d.). Tool making cockatoos adjust the lengths but not the widths of their tools to function. - PLoS One.

Auersperg, A.M.I., Köck, C., Pledermann, A., O’Hara, M. \& Huber, L. (2017). Safekeeping of tools in Goffin's cockatoos, Cacatua goffini. - Anim. Behav. 128: 125-133.

Auersperg, A.M.I., Laumer, I.B. \& Bugnyar, T. (2013b). Goffin cockatoos wait for qualitative and quantitative gains but prefer 'better' to 'more'. — Biol. Lett. 9: 20121092.

Auersperg, A.M.I., Oswald, N., Domanegg, M., Gajdon, G.K., Bugnyar, T., Gajdon, D. \& Bugnyar, T. (2014a). Unrewarded object combinations in captive parrots. - Anim. Behav. Cogn. 1: 470-488.

Auersperg, A.M.I., Szabo, B., von Bayern, A.M.P. \& Bugnyar, T. (2014b). Object permanence in the Goffin cockatoo (Cacatua goffini). - J. Comp. Psychol. 128: 88-98.

Auersperg, A.M.I., Szabo, B., von Bayern, A.M.P. \& Kacelnik, A. (2012). Spontaneous innovation in tool manufacture and use in a Goffin's cockatoo. - Curr. Biol. 22: R903R904.

Auersperg, A.M.I., van Horik, J.O., Bugnyar, T., Kacelnik, A., Emery, N.J. \& von Bayern, A.M.P. (2015). Combinatory actions during object play in psittaciformes (Diopsittaca nobilis, Pionites melanocephala, Cacatua goffini) and corvids (Corvus corax, C. monedula, C. moneduloides). — J. Comp. Psychol. 129: 62-71.

Auersperg, A.M.I., von Bayern, A.M.I., Weber, S., Szabadvari, A., Bugnyar, T. \& Kacelnik, A. (2014c). Social transmission of tool use and tool manufacture in Goffin cockatoos (Cacatua goffini). — Proc. R. Soc. B Biol. Sci. 281: 20140972.

Auersperg, A.M.I., von Bayern, A.M.P., Gajdon, G.K., Huber, L. \& Kacelnik, A. (2011b). Flexibility in problem solving and tool use of kea and New Caledonian crows in a multi access box paradigm. - PLoS One 6: e20231.

Biro, D., Haslam, M. \& Rutz, C. (2013). Tool use as adaptation. - Philos. Trans. R. Soc. B Biol. Sci. 368: 20120408. 
Brejaart, R. (1988). Diet and feeding behaviour of the kea (Nestor notabilis). — Lincoln University, Canterbury (N.Z.).

Cahyadin, Y., Jepson, P. \& Mamoppo, B.I. (1994). Status Cacatua goffini dan Eos reticulata de Kepulauan Tanimbar/The Status of Cacatua goffini and Eos reticulata on the Tanimbar Islands. Bogor.

Call, J. (2013). Three ingredients for becoming a creative tool user. — In: Tool use anim. (Sanz, C., Call, J. \& Boesch, C., eds). Cambridge University Press, Cambridge, p. 3-20.

Crain, B.J., Giray, T. \& Abramson, C.I. (2013). A tool for every job: assessing the need for a universal definition of tool use. - Int. J. Comp. Psychol. 26: 281-303.

Darwin, C. (1859). On the origin of species by means of natural selection, or, the preservation of favoured races in the struggle for life, 1st edn. - John Murray, London.

Darwin, C. \& Wallace, A. (1858). On the tendency of species to form varieties; and on the perpetuation of varieties and species by natural means of selection. - J. Proc. Linn. Soc. London. Zool. 3: 45-62.

Diamond, J. \& Bond, A.B. (1999). Kea, bird of paradox. The evolution and behavior of a New Zealand parrot, Vol. 124. — (Diamond, J. \& Bond, A.B., eds). University of California Press.

Diquelou, M.C., Griffin, A.S. \& Sol, D. (2015). The role of motor diversity in foraging innovations: a cross-species comparison in urban birds behavioral ecology. - Behav. Ecol. 27: 584-591.

Emery, N.J. (2006). Cognitive ornithology: the evolution of avian intelligence. - Philos. Trans. R. Soc. B Biol. Sci. 361: 23-43.

Forshaw, J.M. \& Cooper, W.T. (1989). Parrots of the world, 3rd (rev). - Blanford Press, London.

Fox, E.A., van Schaik, C.P., Sitompul, A. \& Wright, D.N. (2004). Intra-and interpopulational differences in orangutan (Pongo pygmaeus) activity and diet: implications for the invention of tool use. - Am. J. Phys. Anthropol. 125: 162-174.

Fragaszy, D.M. \& Mangalam, M. (2018). Tooling. — Adv. Study Behav. 50: 177-241.

Gray, M.M., Schunke, E.W. \& Cox, J.A. (2016). Tool usage by juvenile Sitta pusilla (brownheaded nuthatch). - Southeast. Nat. 15: N12-N15.

Greenberg, R. (2003). The role of neophobia and neophilia in the development of innovative behaviour of birds. - In: Anim. innov. (Reader, S.M. \& Laland, K.N., eds). Oxford University Press, p. 175-196.

Greenberg, R. \& Mettke-Hofmann, C. (2001). Ecological aspects of neophobia and neophilia in birds. - In: Curr. ornithol., Vol. 16, p. 119-178.

Greer, A.L., Gajdon, G.K. \& Nelson, X.J. (2015). Intraspecific variation in the foraging ecology of kea, the world' s only mountain- and rainforest-dwelling parrot. - N. Z. J. Ecol. 39.

Griffin, A.S. \& Guez, D.G. (2014). Innovation and problem solving: a review of common mechanisms. - Behav. Processes 109: 121-134.

Hamilton, W.D. (1971). Geometry for the selfish herd. — J. Theor. Biol. 31: 295-311.

Hansell, M. \& Ruxton, G. (2008). Setting tool use within the context of animal construction behaviour. — Trends Ecol. Evol. 23: 73-78. 
Haslam, M. (2013). 'Captivity bias' in animal tool use and its implications for the evolution of hominin technology. — Philos. Trans. R. Soc. B Biol. Sci. 368: 20120421.

Heinsohn, R., Zdenek, C.N., Cunningham, R.B., Endler, J.A. \& Langmore, N.E. (2017). Tool-assisted rhythmic drumming in palm cockatoos shares key elements of human instrumental music. — Sci. Adv. 3: 1-7.

Huber, L. \& Gajdon, G.K. (2006). Technical intelligence in animals: the kea model. — Anim. Cogn. 9: 295-305.

Huber, L. \& O'Hara, M. (2016). Extractive foraging hypothesis, the (Parker and Gibson 1997, 2015). - In: Encycl. evol. psychol. sci. (Weekes-Shackelford, V., Shackelford, T.K. \& Weekes-Shackelford, V.A., eds). Springer International Publishing, Cham, p. 1-4.

Hunt, G.R. (2000). Tool use by the New Caledonian crow corvus moneduloides to obtain Cerambycidae from dead wood. - Emu 100: 109-114.

Hunt, G.R., Gray, R.D. \& Taylor, A.H. (2013). Why is tool use rare in animals? - In: Tool use anim. (Sanz, C., Call, J. \& Boesch, C., eds). Cambridge University Press, Cambridge, p. 89-118.

Jepson, P., Brickle, N. \& Chayadin, Y. (2001). The conservation status of Tanimbar corella and blue-streaked lory on the Tanimbar Islands, Indonesia: results of a rapid contextual survey. - ORYX 35: 224-233.

Kacelnik, A., Chappell, J., Kenward, B. \& Weir, A.A.S. (2009). Cognitive adaptations for tool-related behavior in New Caledonian crows. — In: Comp. cogn. explor. anim. intell., Vol. 271. Oxford University Press, Suppl, p. 515-528.

Kenward, B., Rutz, C., Weir, A.A.S., Chappell, J. \& Kacelnik, A. (2004). Morphology and sexual dimorphism of the New Caledonian crow. - Ibis (Lond. 1859) 146: 652-660.

Kenward, B., Schloegl, C., Rutz, C., Weir, A.A.S., Bugnyar, T. \& Kacelnik, A. (2011). On the evolutionary and ontogenetic origins of tool-oriented behaviour in New Caledonian crows (Corvus moneduloides). — Biol. J. Linn. Soc. 102: 870-877.

King, B.J. (1986). Extractive foraging and the evolution of primate intelligence. - Hum. Evol. 1: 361-372.

Lamichhaney, S., Berglund, J., Almén, M.S., Maqbool, K., Grabherr, M., Martinez-Barrio, A., Promerová, M., Rubin, C.J., Wang, C., Zamani, N., Grant, B.R., Grant, P.R., Webster, M.T. \& Andersson, L. (2015). Evolution of Darwin's finches and their beaks revealed by genome sequencing. - Nature 518: 371-375.

Laumer, I.B., Bugnyar, T. \& Auersperg, A.M.I. (2016). Flexible decision-making relative to reward quality and tool functionality in Goffin cockatoos (Cacatua goffiniana). - Sci. Rep. 6.

Laumer, I.B., Bugnyar, T., Reber, S.A. \& Auersperg, A.M.I. (2017). Can hook-bending be let off the hook? Bending/unbending of pliant tools by cockatoos. - Proc. R. Soc. B Biol. Sci. 284: 20171026.

Lefebvre, L., Reader, S.M. \& Sol, D. (2004). Brains, innovations and evolution in birds and primates. - Brain. Behav. Evol. 63: 233-246.

Lefebvre, L.M. \& Bolhuis, J.J. (2003). Positive and negative correlates of feeding innovations in birds: evidence for limited modularity. - In: Anim. innov. Oxford University Press, p. 39-62. 
Lefebvre, L.M., Whittle, P., Lascaris, E. \& Finkelstein, A. (1997). Feeding innovations and forebrain size in birds. - Anim. Behav. 53: 549-560.

Losos, J.B. \& Ricklefs, R.E. (2009). Adaptation and diversification on islands. - Nature 457: 830-836.

Matsui, H., Hunt, G.R., Oberhofer, K., Ogihara, N., McGowan, K.J., Mithraratne, K., Yamasaki, T., Gray, R.D. \& Izawa, E.I. (2016). Adaptive bill morphology for enhanced tool manipulation in New Caledonian crows. - Sci. Rep. 6: 1-11.

Mettke-Hofmann, C., Winkler, H. \& Leisler, B. (2002). The significance of ecological factors for exploration and neophobia in parrots. - Ethology 108: 249-272.

Meyer, D., Zeileis, A. \& Hornik, K. (2006). The strucplot framework: visualizing multi-way contingency tables with vcd. - J. Stat. Softw. 17: 1-48.

Monk, K.A., De Fretes, Y. \& Reksodiharjo-Lilley, G. (1997). The ecology of Nusa Tenggara and Maluku. - Periplus Editions, Singapore.

Morse, D.H. (1964). The use of tools by brown-headed nuthatches. - Wilson Bull. 80: 220224.

O'Hara, M., Gajdon, G.K. \& Huber, L. (2012). Kea logics: how these birds solve difficult problems and outsmart researchers. - In: Locic sensib. (Watanabe, S., ed.). Keio University Press, Tokio, p. 23-37.

O'Hara, M., Auersperg, A.M.I., Bugnyar, T. \& Huber, L. (2015). Inference by exclusion in Goffin cockatoos (Cacatua goffini). — PLoS One (Boraud, T., ed.) 10: e0134894.

O'Hara, M., Mioduszewska, B., Von Bayern, A., Auersperg, A.M.I., Bugnyar, T., Wilkinson, A., Huber, L. \& Gajdon, G.K. (2017). The temporal dependence of exploration on neotic style in birds. - Sci. Rep. 7: 1-9.

Olkowicz, S., Kocourek, M., Lučan, R.K., Porteš, M., Fitch, W.T., Herculano-Houzel, S. \& Němec, P. (2016). Birds have primate-like numbers of neurons in the forebrain. - Proc. Natl. Acad. Sci. 113: 7255-7260.

Olsen, K.M. \& Schaal, B.A. (1999). Evidence on the origin of cassava: phylogeography of manihot esculenta. — Proc. Natl. Acad. Sci. 96: 5586-5591.

Onwueme, I.C. (2002). Cassava in Asia and the Pacific. - In: Cassava biol. prod. util., p. 55-65.

Orenstein, R.I. (1972). Tool-use by the New Caledonian crow (Corvus moneduloides). Auk 89: 674-676.

Osuna-Mascaró, A.J. \& Auersperg, A.M.I. (2018). On the brink of tool use ? Could object combinations during foraging in a feral Goffin's cockatoo (Cacatua goffiniana) result in tool innovations? - Anim. Behav. Cogn. 5: 229-234.

Overington, S.E., Dubois, F. \& Lefebvre, L. (2008). Food unpredictability drives both generalism and social foraging: a game theoretical model. — Behav. Ecol. 19: 836-841.

Parker, S.T. (1996). Apprenticeship in tool-mediated extractive foraging: the origins of imitation, teaching, and self-awareness in great apes. — In: Reach. into thought minds gt. apes, p. $348-370$.

Parker, S.T. (2015). Re-evaluating the extractive foraging hypothesis. — New Ideas Psychol. 37: 1-12. 
Parker, S.T. \& Gibson, K.R. (1977). Object manipulation, tool use and sensorimotor intelligence as feeding adaptations in cebus monkeys and great apes. - J. Hum. Evol. 6: 623-641.

R Core Team (2017). R: a language and environment for statistical computing. — R Foundation for Statistical Computing, Vienna, Austria.

Rutz, C., Bluff, L.A., Reed, N., Troscianko, J., Newton, J., Inger, R., Kacelnik, A. \& Bearhop, S. (2010). The ecological significance of tool use in New Caledonian crows. - Science 329: $1523-1526$.

Rutz, C. \& Deans, S. (2018). Nuthatch uses tool in London park. — Ethology 124: 135-138.

Rutz, C. \& St Clair, J.J.H. (2012). The evolutionary origins and ecological context of tool use in New Caledonian crows. - Behav. Processes 89: 153-165.

Seed, A. \& Byrne, R. (2010). Animal tool-use. — Curr. Biol. 20: R1032-R1039.

Shumaker, R.W., Walkup, K.R., Beck, B.B. \& Burghardt, G.M. (2011). Animal tool behavior: the use and manufacture of tools by animals. - The Johns Hopkins University Press, Baltimore, Maryland.

Smith, E.O. \& Bentley-Condit, V. (2010). Animal tool use: current definitions and an updated comprehensive catalog. - Behaviour 147: 185-32A.

Smith, G.T. \& Moore, L.A. (1992). Patterns of movement in the western long-billed corella Cacatua pastinator in the south-west of western-Australia. — Emu 92: 19-27.

St Amant, R. \& Horton, T.E. (2008). Revisiting the definition of animal tool use. - Anim. Behav. 75: 1199-1208.

Tebbich, S., Griffin, A.S., Peschl, M.F. \& Sterelny, K. (2016). From mechanisms to function: an integrated framework of animal innovation. - Philos. Trans. R. Soc. B Biol. Sci. 371: 20150195.

Tebbich, S., Sterelny, K. \& Teschke, I. (2010). The tale of the finch: adaptive radiation and behavioural flexibility. — Philos. Trans. R. Soc. Lond. B. Biol. Sci. 365: 1099-1109.

Tebbich, S., Taborsky, M., Fessl, B. \& Dvorak, M. (2002). The ecology of tool-use in the woodpecker finch (Cactospiza pallida). - Ecol. Lett. 5: 656-664.

Teschke, I., Cartmill, E.A., Stankewitz, S. \& Tebbich, S. (2011). Sometimes tool use is not the key: no evidence for cognitive adaptive specializations in tool-using woodpecker finches. - Anim. Behav. 82: 945-956.

Thomas, R.J., Lello, J., Medeiros, R., Pollard, A., Robinson, P., Seward, A., Smith, J., Vafidis, J. \& Vaughan, I.R. (2017). Data analysis with R statistical software. A guidebook for scientists. - Eco Explore, Cardiff.

Troscianko, J., von Bayern, A.M.P., Chappell, J., Rutz, C. \& Martin, G.R. (2012). Extreme binocular vision and a straight bill facilitate tool use in New Caledonian crows. - Nat. Commun. 3: 1110.

Werdenich, D. \& Huber, L. (2006). A case of quick problem solving in birds: string pulling in keas, Nestor notabilis. — Anim. Behav. 71: 855-863.

Wickham, H. (2009). ggplot2. - Media, Vol. 35.

Williams, G.C. (1966). Adaptation and natural selection. - Princeton University Press, Princeton, Vol. 1996 re-pr. 


\section{Appendix}

In order to compute an overdispersion factor for generalised linear mixed models we employed an overdispersion function for $\mathrm{R}$ as suggested by Thomas et al. (2017) and Bolker (https://bbolker.github.io/mixedmodelsmisc/glmmFAQ.html\#overdispersion (accessed 6 October 2018)):

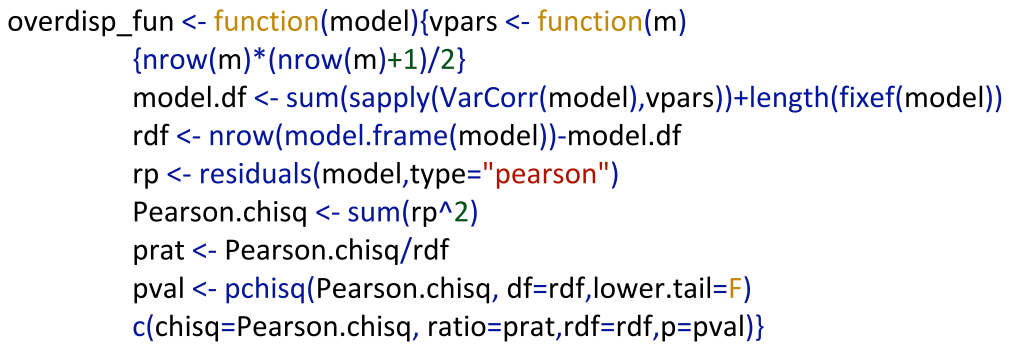

Table A1.

Simultaneous contrast statistics for behavioural categories; reported pvalues are adjusted for multiple testing employing the 'holm' correction method (model: $\log ($ Encounters $/$ Sitevisits $) \sim$ Behaviour + Social + Season $*$ Habitat $+(1 \mid$ Site $))$.

\begin{tabular}{lrrrrr}
\hline & \multicolumn{1}{c}{$\beta$} & SE & $z$ value & \multicolumn{1}{c}{$p$} & Sig. \\
\hline Foraging vs. Flying & -0.93 & 0.13 & -7.393 & $<0.001$ & $* * *$ \\
Substrate manipulation vs. Flying & -102.67 & 0.16 & -6.497 & $<0.001$ & $* * *$ \\
Perching vs. Flying & -0.10 & 0.09 & -1.145 & 0.853 & \\
Play vs. Flying & -0.82 & 0.17 & -4.751 & $<0.001$ & $* * *$ \\
Preening vs. Flying & -0.60 & 0.11 & -5.261 & $<0.001$ & $* * *$ \\
Substrate manipulation vs. Foraging & -0.10 & 0.18 & -0.535 & 0.994 & \\
Perching vs. Foraging & 0.83 & 0.13 & 6.440 & $<0.001$ & $* * *$ \\
Play vs. Foraging & 0.11 & 0.19 & 0.576 & 0.992 & \\
Preening vs. Foraging & 0.33 & 0.14 & 2.313 & 0.176 & \\
Perching vs. Substrate manipulation & 0.92 & 0.16 & 5.809 & $<0.001$ & $* * *$ \\
Play vs. Substrate manipulation & 0.21 & 0.21 & 0.968 & 0.922 & \\
Preening vs. Substrate manipulation & 0.43 & 0.17 & 2.512 & 0.112 & \\
Play vs. Perching & -0.72 & 0.17 & -4.138 & $<0.001$ & $* * *$ \\
Preening vs. Perching & -0.49 & 0.12 & -4.282 & $<0.001$ & $* * *$ \\
Preening vs. Play & 0.22 & 0.18 & 1.224 & 0.814 & \\
\hline
\end{tabular}

*** $p<0.001,{ }^{* *} p<0.01$ and ${ }^{*} p<0.05$. 
Table A2.

Simultaneous contrast statistics for the interaction of habitat and season; reported $p$ values are adjusted for multiple testing employing the 'holm' correction method (model: $\log ($ Encounters $/$ Sitevisits $) \sim$ Behaviour + Social + Season $*$ Habitat $+(1 \mid$ Site $))$.

\begin{tabular}{|c|c|c|c|c|c|}
\hline & $\beta$ & SE & $z$ value & $p$ & Sig \\
\hline Rain.Field vs. Dry.Field & 0.22 & 0.14 & 1.542 & 0.741 & \\
\hline Dry.Forest vs. Dry.Field & 105.00 & 0.29 & 3.587 & 0.006 & $* *$ \\
\hline Rain.Forest vs. Dry.Field & 0.97 & 0.35 & 2.749 & 0.087 & . \\
\hline Dry.Grassland vs. Dry.Field & 0.89 & 0.40 & 2.245 & 0.277 & \\
\hline Rain.Grassland vs. Dry.Field & -0.38 & 0.47 & -0.813 & 0.990 & \\
\hline Dry.Shrubs vs. Dry.Field & -0.21 & 0.31 & -0.672 & 0.997 & \\
\hline Rain.Shrubs vs. Dry.Field & -0.31 & 0.31 & -0.986 & 0.968 & \\
\hline Dry.Forest vs. Rain.Field & 0.83 & 0.29 & 2.848 & 0.067 & . \\
\hline Rain.Forest vs. Rain.Field & 0.75 & 0.35 & 2.130 & 0.342 & \\
\hline Dry.Grassland vs. Rain.Field & 0.67 & 0.40 & 1.693 & 0.640 & \\
\hline Rain.Grassland vs. Rain.Field & -0.60 & 0.47 & -1.282 & 0.880 & \\
\hline Dry.Shrubs vs. Rain.Field & -0.43 & 0.31 & -1.393 & 0.828 & \\
\hline Rain.Shrubs vs. Rain.Field & -0.53 & 0.31 & -1.701 & 0.634 & \\
\hline Rain.Forest vs. Dry.Forest & -0.08 & 0.27 & -0.296 & 0.999 & \\
\hline Dry.Grassland vs. Dry.Forest & -0.16 & 0.378 & -0.421 & 0.999 & \\
\hline Rain.Grassland vs. Dry.Forest & -143.36 & 0.46 & -3.144 & 0.0281 & $*$ \\
\hline Dry.Shrubs vs. Dry.Forest & -125.75 & 0.28 & -4.415 & $<0.001$ & $* * *$ \\
\hline Rain.Shrubs vs. Dry.Forest & -135.87 & 0.29 & -4.700 & $<0.001$ & $* * *$ \\
\hline Dry.Grassland vs. Rain.Forest & -0.08 & 0.43 & -0.188 & 1.000 & \\
\hline Rain.Grassland vs. Rain.Forest & -135.47 & 0.50 & -2.727 & 0.093 & . \\
\hline Dry.Shrubs vs. Rain.Forest & -117.86 & 0.35 & -3.397 & 0.013 & $*$ \\
\hline Rain.Shrubs vs. Rain.Forest & -127.98 & 0.35 & -3.650 & 0.005 & $* *$ \\
\hline Rain.Grassland vs. Dry.Grassland & -127.46 & 0.32 & -3.936 & 0.002 & $* *$ \\
\hline Dry.Shrubs vs. Dry.Grassland & -109.85 & 0.39 & -2.812 & 0.074 & . \\
\hline Rain.Shrubs vs. Dry.Grassland & -119.97 & 0.39 & -3.046 & 0.038 & * \\
\hline Dry.Shrubs vs. Rain.Grassland & 0.18 & 0.47 & 0.377 & 0.999 & \\
\hline Rain.Shrubs vs. Rain.Grassland & 0.07 & 0.47 & 0.159 & 1.000 & \\
\hline Rain.Shrubs vs. Dry.Shrubs & -0.10 & 0.12 & -0.875 & 0.984 & \\
\hline
\end{tabular}
${ }^{* * *} p<0.001,{ }^{* *} p<0.01$ and ${ }^{*} p<0.05$.

Video 1. Sample video of wild Goffin's cockatoo digging for cassava roots; footage taken in the aviary during a capture-release study.

Video 2. Example of wild Goffin's cockatoo foraging on coconut water and endosperm.

Video 3. Sample video of wild Goffin's cockatoos consuming larvae of the family Cerambycidae sp.; footage taken in the aviary during a capturerelease study. 
Video 4. Sample video of wild Goffin's cockatoo foraging for larvae of the family Cerambycidae sp. within a rotting wooden log; individual using one of the toes to extract the larvae at 14 seconds; footage taken in the aviary during a capture-release study. 